\title{
Editorial
}

\section{Ações para a promoção da igualdade de gênero e direitos LGBTI na Uniōo Europeia ${ }^{1}$}

Actions for the promotion of gender equality and LGBTI rights in the European Union DOI: $10.5752 /$ P.1809-6182.2016v13.n3.pl40

Pedro Barbabela de Mello Vilela²

Fellipe Bambino Ribeiro Silva ${ }^{3}$

Helen Cardenuto Lima ${ }^{4}$

João Pedro Silveira Martins ${ }^{5}$

Letícia Maria Antunes do Carmo ${ }^{6}$

\section{RESUMO}

Recebido em: 02 de maio de 2016

Aprovado em: 24 de junho de 2016

Este artigo busca verificar a supranacionalidade das açóes para a promoção da igualdade de gênero e das açôes para promoção dos direitos LGBTI realizadas no âmbito da União Europeia no periodo compreendido entre 2005 e 2015. Espera-se, através de uma comparação entre três açôes de cada uma das áreas citadas acima, compreender o grau de compartilhamento de soberania dos paises do bloco nestas duas áreas temáticas, que, não apenas estão presentes desde a criação do mesmo, mas também são temas cada vez mais discutidos nas agendas atuais da União Europeia.

Palavras-chave: União Europeia. Igualdade de gênero. Direitos LGBTI.

\section{ABSTRACT}

This article aims to verify the supranational actions towards the promotion of gender equality and actions to promote LGBTI rights held within the European Union between the years of 2005 and 2015. It is expected, through a comparison between three actions of each of the above mentioned areas, to understand the extent of the member States sharing sovereignty in these two thematic areas, which not only have been present since the creation of the Union, but are also increasingly discussed themes in the current agendas of the European Union.

Key words: European Union. Gender equality. LGBTI rights.

\footnotetext{
1. Artigo derivado do trabalho apresentado na disciplina Estudos Regionais: Integração Regional Teorias e Processos do curso de graduação em Relaçôes Internacionais da Pontifícia Universidade Católica de Minas Gerais.

2. Bacharel em Relações Internacionais pela Pontifícia Universidade Católica de Minas Gerais. orcid.org/0000$\underline{0003-1360-4455}$

3. Graduado em Relaçóes Internacionais pela PUC Minas. orcid.org/0000-0001-6466-2677

4. Graduada em Relaçôes Internacionais pela PUC Minas. orcid.org/0000-0002-8554-620X

5. Mestrando em Sociologia pela UFRGS. orcid.org/0000-0002-7545-7991

6. Graduada em Relações Internacionais pela PUC Minas. orcid.org/0000-0003-3158-9295
} 


\section{Introdução}

Questôes relacionadas ao tratamento igualitário entre mulheres e homens e sobre os direitos da população LGBTI (Lésbicas, Gays, Bissexuais, Transexuais e Intersexuais) são temas fundamentais na União Europeia (EU) desde sua formulação e criação. Os princípios de igualdade de gênero e de não discriminação são centrais para todas as atividades da instituição e foram acordados por meio de diversos tratados ao longo dos anos (EUROPEAN COMISSION, 2011). Açóes voltadas para a promoção da igualdade de gênero e de direitos LGBTI são amplamente discutidas no âmbito do bloco e recebem grande atençấo de órgãos como a Comissão Europeia e o Parlamento Europeu.

Este artigo pretende avaliar o caráter supranacional das açôes citadas acima, comparado as açôes que promovem a igualdade de gênero e as que promovem os direitos LGBTI, com o objetivo de verificar em qual das duas temáticas há uma maior delegação de soberania por parte dos Estados-membros da União Europeia. Desta forma, a pergunta que guia o artigo é: dentre as açôes de promoção de gênero e direitos LGBTI, quais apresentaram caráter mais supranacional no âmbito da União Europeia durante o período de 2005 a 2015? E por que?

Para o desenvolvimento do artigo serão primeiramente apresentadas as principais convençôes da Uniâo Europeia que possuem relevância para a igualdade de gênero e direitos LGBTI. É necessária, também, a mobilização de alguns conceitos da teoria neofuncionalista de integração regional e do construtivismo social, para possibilitar uma melhor compreensão das açôes dos órgãos da União Europeia, como a criação de legislação e formulação de políticas. Para que fosse possível a comparação das açóes de cada temática, foram selecionadas três políticas de cada uma destas, que foram apresentadas separadamente, sendo elas: paridade salarial, violência e aborto (referente à igualdade de gênero) e casamento homoafetivo, homotransfobia e proteção aos transgêneros (referentes aos direitos LGBTI). Foram escolhidas as políticas que mobilizam os principais esforços dos órgãos da União Europeia nas respectivas áreas ou as ações que, por apresentarem grandes resistências (não apenas institucionais) estâo no centro das pautas de reinvindicaçâo dos movimentos sociais. Assim foi possível verificar, dentre as açōes voltadas para gênero e direitos LGBTI, qual das duas possui um caráter mais supranacional, o que foi apresentado nas consideraçôes finais.

\section{Convenções básicas de igualdade de gênero e direitos LGBTI na União Europeia}

No que tange à promoção da igualdade de gênero na União Europeia deve-se ter em mente os seguintes tratados: o Tratado de Roma (1957) fortaleceu a necessidade de paridade salarial entre homens e mulheres; O Tratado de Amsterdã (1997) lutou para colocar a igualdade de gênero como tarefa fundamental da instituiçáo e iniciou o combate à desigualdade e à discriminação das mulheres; $\mathrm{A}$ Escritura de Direitos Fundamentais da União Europeia (2000) assegurou a igualdade de gênero em todas as áreas da sociedade, incluindo emprego, salário e pagamento, e reafirmou a necessidade de lutar contra a discriminação; $\mathrm{O}$ Tratado da União Europeia de 2009 obrigou os Estados-membros a criarem políticas contra a discriminação e favoráveis à igualdade de gênero e o Tratado para Funcionamento da União Europeia (2009) ofereceu apoio para acabar com as desigualdades entre homens e mulheres, além de estipular que se deve combater a discriminação baseada em sexo, raça, etnia, religiẫo, deficiência, idade ou orientação sexual (EUROPEAN COMISSION, 2011). A legislação da 
Uniâo Europeia não mede esforços para a defesa das mulheres. Foram 15 diretivas adotadas entre os anos de 1975 e 2010 com questóes relacionadas à igualdade de gênero. Estas incluem leis sobre paridade de salários, fim da discriminação nos programas de previdência social, proteção para licença maternidade e proteçáo às mulheres gestantes (EUROPEAN COMISSION, 2011). Há reuniōes frequentes no âmbito da Comissão Europeia para intercâmbio de experiências, informaçóes e novas formas de aplicar estas práticas acordadas (EUROPEAN COMISSION, 2011).

Já em relação aos direitos LGBTI, os jovens são particularmente vulneráveis, experimentando a alienação das redes familiares e de amizade, o assédio na escola e invisibilidade, o que pode levar, em alguns casos de insucesso escolar, ao abandono escolar, problemas de saúde mental e falta de moradia, já que muitas vezes estes jovens são expulsos de casa. Tal discriminação impede que as pessoas LGBTI tenham igualdade de acesso aos bens sociais básicos, como o emprego, cuidados de saúde, educação e habitação, o que pode levar estes grupos a tornarem-se socialmente excluídos. Embora o combate à exclusão social nos Estados-membros da UE tenha sido um objetivo desde o lançamento da Estratégia de Lisboa em $2000^{7}$, pouca atenção tem sido dada para a exclusão que as pessoas LGBTI sofrem no contexto da política social europeia, e em particular das estratégias de inclusão social da UE.

Para compreendermos o panorama geral da situação dos LGBTI na Europa, vê-se como necessário o conhecimento dos mecanismos e convençóes da UE no que diz respeito à garantia de direitos a essa minoria. Assim podemos citar três deles: a Convenção Europeia para a Proteção dos Direitos Humanos e Liberdades Fundamentais, a Conven-

7. A Estratégia de Lisboa (2000) refere-se às açôes de readaptação de processos voltados para o crescimento econômico do bloco e para aumento da coesão no âmbito social (CONSELHO EUROPEU DE LISBOA, 2006) ção de Prevenção e Combate da violência contra mulheres e violência doméstica e a Carta Social Europeia (COUNCIL OF EUROPE, 2014).

A Convenção Europeia para a Proteção dos Direitos Humanos e Liberdades Fundamentais ou, como também é conhecida, a Convenção Europeia de Direitos Humanos, foi escrita em 1950 e assinada em 1953. Tal Convenção proíbe a discriminação ou perseguiçáo de qualquer natureza contra indivíduos, ainda que não mencione explicitamente os termos orientação sexual ou identidade de gênero (COUNCIL OF EUROPE, 2014). A proteção dos direitos humanos das pessoas LGBTI no âmbito da Convenção Europeia dos Direitos Humanos deriva, em primeiro lugar, do artigo 14, que proíbe qualquer forma de discriminação no exercício dos direitos e liberdades garantidos pela Convenção (COUNCIL OF EUROPE, 2014).

Desta forma, deve-se reconhecer o papel do Tribunal Europeu dos Direitos do Homem (CEDH), que é um tribunal supranacional estabelecido pela Convenção Europeia dos Direitos Humanos e recebe denúncias de violaçóes à Convenção. Conforme acordado no documento, as queixas podem ser apresentadas por indivíduos ou Estados.

A jurisprudência da CEDH tem sido essencial no combate à discriminação em razão da orientaçáo sexual e identidade de gênero, reconhecendo regularmente violaçóes dos vários artigos da Convenção na medida em que os direitos humanos das pessoas LGBTI estavam em jogo (COUNCIL OF EUROPE, 2014, p.1, traduçáo nossa ${ }^{8}$ ).

A Convenção de Prevenção e Combate da violência contra mulheres e violência doméstica é o acordo internacional que inclui proteção para as mulheres transexuais, lésbicas e bissexuais. $\mathrm{O}$ artigo

8. The case-law of the ECHR has been essential in combating discrimination on grounds of sexual orientation and gender identity, regularly recognising violations of the various articles of the Convention insofar as the human rights of LGBT persons were at stake. 
sobre a não discriminação protege essas mulheres, abrangendo a orientação sexual e identidade de gênero. Desta forma, as partes reconhecem que as mulheres Lésbicas, Bissexuais e Transexuais (LBT) são vulneráveis à violência, devido à discriminação múltipla, e exigem medidas específicas de proteção (COUNCIL OF EUROPE, 2014).

Por fim, existe ainda a Carta Social Europeia, um documento complementar da Convenção Europeia de Direitos Humanos que garante os direitos sociais e econômicos dos cidadãos europeus. Foi adotada em 1961 e revista em 1996. Os direitos garantidos pela Carta referem-se à habitação, saúde, educação, emprego, proteção jurídica e social, livre circulação de pessoas e não discriminação (COUNCIL OF EUROPE, 2014).

Além dos documentos mencionados acima, o Conselho da Europa desenvolve um projeto intitulado: Combating discrimination on the grounds of sexual orientation or gender identity, com foco na adoção e suporte de medidas e atividades relevantes, voltada para o desenvolvimento de estratégias nacionais e/ ou planos de ação. O projeto busca desenvolver uma política LGBTI forte, que envolve vários setores e busca fortalecer os direitos humanos das pessoas LGBTI e apoiar a luta nacional contra a discriminaçáo com base na orientação sexual ou identidade de gênero (COUNCIL OF EUROPE, 2014).

\section{Teorias e Conceitos}

Propóe-se aqui fazer uma análise comparativa transversal que avaliará açóes realizadas dentro da Uniáo Europeia para as questóes de gênero e de pessoas LGBTI. Esta comparação considerará três açóes para questóes de gênero, sendo elas a paridade salarial, violência e aborto, e três açóes relativas aos direitos LGBTI, sendo elas o casamento homoafetivo, homotransfobia e proteção aos transgêneros.
Uma vez que o foco são as ações da União Europeia, o presente artigo adota um nível de análise regional. Desta forma, as unidades de análise são o Conselho da União Europeia - responsável por coordenar as políticas entre os Estados-membros do bloco; o Parlamento Europeu - que adota legislaçôes juntamente com o Conselho da União Europeia; a Comissão Europeia - responsável por defender os interesses gerais da UE por meio da apresentação de propostas legislativas; e também os grupos da sociedade civil, que por sua vez ajudam a levar as questốes aos órgáos oficiais do bloco, dentre eles o International LGBTI Associação Internacional de Gays e Lésbicas (ILGA) e o Transgender Europe (TGEU) (UNIÃO EUROPEIA, 2016).

O presente trabalho mobiliza a teoria de integração regional neofuncionalista como modelo de análise para a pesquisa. Ernst B. Haas define integração regional como um processo em que

[...] os Estados deixam de ser unicamente soberanos, e como e porque eles voluntariamente se fundem e se misturam com seus vizinhos e, perdem os atributos factuais de soberania enquanto adquirem novas técnicas para a resolução de conflitos entre eles (HAAS, 1971, p. 610, tradução nossa).

Partindo do conceito de integração regional, serão mobilizadas algumas outras definiçóes que darão suporte ao estudo de caso. A primeira delas é a cooperação, definida por Keohane (1984) como o processo no qual os atores ajustam seu comportamento para as preferências atuais ou antecipadas de outros através da coordenação das políticas. É relevante também o conceito de integração, que se refere a um processo no qual as relaçôes entre as unidades sociais autônomas mudam de tal forma que alteram a autonomia de cada um e os tornam parte de um agregado maior (HAAS, 2008).

A cooperaçáo e o posterior maior grau de integração na União Europeia geraram o que Karl Kaiser chama de sociedade transnacional, definida 
como "um sistema de interação, num domínio particular, entre atores sociais pertencentes a sistemas nacionais diferentes" (KAISER, 1990, p. 275). É importante ressaltar que a União Europeia, em seu complexo arranjo institucional, possui instituições supranacionais e intergovernamentais, que atuam de formas distintas. As instituiçóes supranacionais caracterizam-se por uma estrutura funcional que nâo é vinculada apenas aos interesses dos Estados, uma vez que suas decisões se sobrepóem às leis nacionais dos Estados-membros da União (BALE, 2008). As instituiçôes intergovernamentais por sua vez, apresentam uma configuração com foco no Estado, obedecendo uma lógica de coordenação interestatal, na qual os interesses destes são articulados e sua atuação depende da concordância dos Estados-membros, que podem em determinados momentos reservar-se o direito de ignorarem decisóes contrarias a seus interesses nacionais (COUTINHO, 2016; BALE, 2008).

Como mencionado acima, as açôes que serão analisadas são promovidas e desenvolvidas também por alguns dos órgãos da União Europeia. Dentre eles, o Parlamento Europeu e a Comissão Europeia possuem caráter supranacional, enquanto o Conselho da União Europeia consiste em uma instituição Intergovernamental (MAMEDE, 2014).O funcionamento destes órgãos, sejam eles supranacionais ou intergovernamentais, é fundamental para que a Uniấo Europeia seja capaz de agir de acordo com seus propósitos.

O conceito de spillover é importante para compreender a evolução do processo de integraçấo do bloco ao longo dos anos, bem como questôes referentes à igualdade de gênero e aos direitos LGBTI chegaram às pautas de discussóes atuais. O spillover pode ser definido como a ideia de que a integração gera mais integração, transbordando de uma área para outra de maneira harmoniosa, seguindo uma lógica inerente da integração através de uma maior interdependência tanto funcional quanto econômica (NIEMANN; SCHMITTER, 2009). Para que o processo de spillover ocorra, as instituições supranacionais são fundamentais, já que é a partir destas que acontece o compartilhamento de soberania no bloco.

O spillover tem também relaçáo direta com dois outros conceitos, o de harmonização e aprofundamento. Segundo Leach (2000), o processo de harmonização no bloco teve início com a criação de um mercado comum, mas atualmente diz respeito à existência de um consenso entre os países da UE acerca das políticas a serem desenvolvidas em diversas áreas. $\mathrm{O}$ aprofundamento, por sua vez, consiste no aumento do grau de integração na União Europeia, a partir da inclusão de novas áreas e temas substantivos nas pautas de discussóes do bloco (LEACH, 2000).

Alguns conceitos do construtivismo social também podem ser utilizados para complementar a análise proposta, como os conceitos de identidade, interação social e realidade social. Para o construtivismo social, a realidade social não é dada, mas sim construída e reproduzida através da prática (RISSE, 2009). As identidades dos agentes são construídas e reconstruídas através de interaçôes históricas subjetivas. Assim, Berger (1966) compreende identidade como algo inerente relacional "identidade, com os seus elementos da realidade psicológica, é sempre a identidade dentro de um mundo específico, socialmente construído." (BERGER, 1966, p. 111, tradução nossa ${ }^{9}$ ). A interação social, então, começa a ser entendida como um meio pelo qual ocorre a reprodução das estruturas sociais em uma realidade social, entendida como um conjunto de regras e acordos intersubjetivos, construído pelos atores (RAMOS, MARQUES, JESUS, 2009). Desta for-

9. Identity, with its appropriate attachments of psychological reality, is always identity within a specific, socially constructed world. 
ma, o construtivismo deixa claro como as identidades, socialmente e historicamente incorporadas, podem constituir um significativo obstáculo para o aprofundamento da cooperação (SANTOS, 2009).

\section{Ações no âmbito europeu para a promoção da igualdade de gênero}

\section{Paridade salarial}

A disparidade salarial (gender pay gap) consiste na diferença, em média, entre os salários (por hora) recebidos por homens e mulheres em toda a economia (EUROPEAN COMMISSION, 2014). Atualmente, mulheres continuam recebendo menos que homens, mesmo com as mesmas ocupaçōes e níveis de escolaridade. De acordo com dados do ano de 2015, em média, para cada $1 €$ recebido por homens na União Europeia, as mulheres recebem apenas $0,84 €$. Sáo vários os fatores que contribuem para essa disparidade, e, no intuito de reduzi-la, a Comissão Europeia adota uma estratégia com múltiplas frentes (EUROPEAN COMISSION, 2015).

A Comissão Europeia é o órgão responsável pelo monitoramento da aplicação e enforcement da Legislação de Paridade Salarial nos Estados-membros, vigente desde o ano de 2006. Esta legislação, adotada através da Diretiva ${ }^{10}$ 2006/54/EC, garante a aplicação do princípio da igualdade de oportunidades e de tratamento entre homens e mulheres em matéria de emprego e ocupação em todos os Estados-membros da União Europeia (EUROPEAN COMISSION, 2015).

A Comissão também é responsável por organi-

10. Diretivas são "atos legislativos" que vinculam os Estados-membros quanto a um objetivo a ser alcançado por todos os membros da Uniáo Europeia, mas náo determinam a estratégia que a país deve utilizar para alcançá-lo. Desta forma, cabe ao país determinar a forma e o meio para cumprir diretivas. Seu legislativo deve elaborar suas próprias leis para adaptar o direito nacional aos objetivos dispostos na diretiva (EUROPEAN UNION, 2015). zar, anualmente, o European Equal Pay Day, evento que arrecada fundos para projetos transnacionais, visando a redução da disparidade salarial. Em 2014 o evento forneceu financiamento para oito projetos, dentre estes um projeto para o desenvolvimento de uma ferramenta que permite às empresas realizar o cálculo de sua própria disparidade salarial, bem como analisar fatores que contribuem para esta, que já está disponível para companhias na França, Reino Unido, Finlândia, Portugal e Polônia. Outro projeto financiado no mesmo ano teve como objetivo o desenvolvimento de estratégias transnacionais e alianças com sindicatos e organismos da sociedade civil para combater as disparidades salariais. Ainda no ano de 2014, a Comissão Europeia adotou a Recomendação C(2014) 1405, referente ao reforço do princípio da igualdade de remuneração entre homens e mulheres através da transparência, recomendando a criação de uma base de dados com medidas concretas e efetivas para a promoção de maior transparência nos pagamentos salariais (EUROPEAN COMISSION, 2015).

Assim, é possível perceber que a Comissão Europeia atua de forma relevante em questóes relacionadas à paridade salarial. Além de existir uma legislação específica sobre o tema não se observa nenhuma grande resistência dos Estados-membros quanto ao tópico. Existem, ainda, projetos transnacionais que buscam atingir a igualdade de salários entre homens e mulheres.

\section{Violência de gênero}

A violência de gênero é a violência que é destinada a uma pessoa em decorrência de seu gênero ou que afeta pessoas de um determinado sexo de maneira desproporcional, podendo ser de natureza física, psicológica, sexual e/ou econômica. A violência contra a mulher é uma representação extrema da desigualdade de gênero e uma violação dos direitos humanos (EUROPEAN COMMISSION, 2015). 
Este é um problema que afeta a sociedade europeia como um todo e de acordo com dados do Instituto Europeu para a Igualdade de Gênero (2014) seus custos são estimados em $€ 258$ bilhôes a cada ano. As estatísticas acerca da violência de gênero ainda são alarmantes. Estima-se que, em média, na Uniāo Europeia, a cada minuto, 7 mulheres sejam vítimas de estupro ou outra forma de agressão sexual, 25 sejam vítimas de violência física e 74 sejam vítimas de assédio sexual (EUROPEAN COMISSION, 2015).

Desta forma, a Comissão Europeia realiza esforços voltados para a prevençấo de todas as formas de violência, assistência às vítimas, conscientização da população e armazenamento e análise de dados sobre esse tipo de violação. No decorrer dos últimos anos, a Uniáo Europeia buscou desenvolver e aplicar medidas e políticas para o combate da violência de gênero. As Diretivas 2011/36/EU (referente ao combate e prevenção do tráfico de pessoas e proteção das vítimas) e 2011/92/EU (sobre o combate ao abuso e exploração sexual de crianças e pornografia infantil), ambas dos anos de 2011, estabelecem medidas efetivas para prevenir, apoiar e proteger as vítimas de violência e punir os perpetradores destas modalidades de crime (EUROPEAN COMISSION, 2015).

A Diretiva 2012/29/EU, do ano de 2012, acerca do estabelecimento de direitos mínimos para todas as vítimas, estipula padróes mínimos de apoio e proteção das vítimas. $\mathrm{O}$ documento determina que as vítimas sejam tratadas com respeito por policiais, promotores e juízes, recebam informaçōes compreensíveis sobre seus direitos, sejam protegidas de intimidação e retaliação durante as investigaçôes e dinâmicas da Corte, tenham o direito de recorrer da decisão da Corte, entre outros. A Diretiva 2011/99/EU e a Regulação 606/2013, dos anos de 2011 e 2013, respectivamente, oferecem respaldo legal para que vítimas de violência de gênero sejam protegidas em todo o território da União Europeia caso viajem ou se mudem, de forma que ordens de restrição emitidas em um país são reconhecidas nos Estados-membros do bloco (EUROPEAN COMISSION, 2015).

No ano de 2013, a Comissão Europeia também emitiu um comunicado, COM (2013) 833, explicitando os compromissos da Comissão com a eliminação da Mutilação Genital Feminina. O órgão afirmou seu comprometimento com a prevenção da Mutilaçãao Genital Feminina, promoção do suporte às vítimas e apoio ao julgamento por parte dos Estados-membros. No ano de 2014 o foco do trabalho da Comissão Europeia foi na implementação e avaliação das medidas legais e políticas já adotadas. A Comissão auxilia os Estados-membros com a adaptação das leis nacionais às determinaçóes das diretivas, por meio de açóes como, por exemplo, a realização de workshops para representantes dos países (EUROPEAN COMISSION, 2015).

A Comissão Europeia também financia diversas campanhas de sensibilização nos Estados-membros e apoia organizaçóes populares e ONGs que trabalham para prevenir a violência contra a mulher. Alguns exemplos são o apoio oferecido às atividades do European Women's Lobby (EWL), desde a década de 1990, a maior rede de organizaçóes de mulheres na União Europeia, e o apoio à Women Against Violence Europe (WAVE) nos últimos sete anos, uma Organização Não Governamental (ONG) que trabalha na assistência às vítimas. Outro exemplo foi a realização, no ano de 2013, de uma parceria com universidades e ONGs para a criação do REPLACE FGM, um acervo digital disponibilizado aos países, que apresenta um guia prático de como utilizar a mudança comportamental em comunidades específicas para erradicar a mutilação genital feminina (EUROPEAN COMISSION, 2015).

Desta forma, a violência de gênero mostra-se como um problema que recebe grande atenção da Comissão Europeia e o órgão age de forma incisiva 
na erradicação desta violação. A legislação existente acerca da questão é extensa, são várias as diretivas aprovadas pela Comissão que tratam deste tipo de abuso, sendo possível perceber um fortalecimento da atuação do órgão ao longo dos anos. É interessante notar, ainda, que no que se refere à violência de gênero existe um esforço voltado para um trabalho conjunto com ONGs e Sociedade Civil.

\section{Aborto}

$\mathrm{Na}$ medida em que as naçôes ocidentais laicizaram o seu sistema político, espera-se que a decisão sobre a manutenção da gestação das mulheres não esteja envolvida no campo político (ROY, 2016). Assim, o aborto deveria ser uma decisão individual, desvinculada de ideologias religiosas ou partidárias, que cabe somente à mulher, relacionada ao seu próprio corpo. Na União Europeia a situação do aborto possui extremos opostos. Por um lado, alguns países da Europa Ocidental possuem as menores taxas de aborto do mundo, sendo de 12 a cada 1000 mulheres, de acordo com a instituição European Health for All. No entanto, no Leste Europeu ${ }^{11}$ há as maiores taxas de aborto no mundo, tendo havido mais abortos que nascimentos durante o início do século XXI (SEDGH et al. 2007).

A maioria desses abortos ocorreu por uma gravidez indesejada por falha dos métodos contraceptivos, estupros e mesmo questóes de saúde. Quase todos os países europeus possuem legislação que autoriza o aborto para risco de morte da mulher ou para preservar sua saúde mental ou física. A grande maioria permite aborto para má formação do feto, casos de estupro e razóes sociais ou econômicas. Em Malta e Andorra, no entanto, o aborto é proibido em qualquer circunstância e na Polônia e Irlanda há severas limitaçôes para a prática, o que obriga as

11. Os países em questão são a Bielorrússia, Bulgária, República Tcheca, Hungria, Polônia, Moldova, România, Federação Russa, Eslováquia e Ucrânia. mulheres a buscarem alternativas extremamente perigosas para conseguir abortar (SEDGH et al. 2007).

Informações sobre o aborto são muito importantes para construção de políticas públicas exequíveis e de sucesso na área do planejamento familiar, de educação sexual e de proteção da mulher. As estatísticas, no entanto, podem gerar confusão, pois muitas mulheres não se sentem confortáveis para relatar suas experiências com aborto e apenas aqueles realizados em hospitais e clínicas públicas são seguramente contabilizados (SEDGH et al. 2007).

Embora haja um comitê especial para igualdade de gênero no Parlamento Europeu, que lutou nos últimos anos para proteção da mulher gestante para sua autonomia de decisão sobre o aborto, a situação dentro da União Europeia não possui grandes avanços para legislação em comum ou programas de proteção destes casos. A França esteve trabalhando para criar uma posição comum dentro da UE no Conselho de Assuntos Exteriores, mas náo conseguiu evoluções significativas (BARBIÈRE, 2015).

A principal razão é a disparidade entre os países da comunidade europeia sobre a questão. De um lado, há países que lutam pelos direitos de reprodução, sobretudo a França, Alemanha, Reino Unido, Portugal, Grécia, Holanda e países Nórdicos, mas por outro há países que se opõem contra a questão, notadamente Hungria e Malta. A oposição de Malta para esses direitos atrapalha o avanço das negociaçóes sobre políticas em comum e programas da própria comissão europeia na questão e possui fortes aliados, como a Espanha, Polônia, Hungria e Irlanda (BARBIÈRE, 2015).

As discussōes sobre o aborto estiveram presentes em algumas reuniōes envolvendo as medidas europeias para as Metas de Desenvolvimento Sustentável Pós-2015 das Naçôes Unidas, mas a União Europeia está longe de possuir uma agenda compartilhada sobre o assunto. $\mathrm{Na}$ apresentação dos planos de ação de 2015 a 2020, da Comissão Europeia, há a 
proposta de discutir a questáo do aborto como parte integral do documento, mas não há apoio total dos ministros europeus (BARBIÈRE, 2015).

\section{Ações no âmbito europeu para a promoção da igualdade baseado na Orientação Sexual e na Identidade de Gênero}

\section{Casamento entre pessoas LGBTI}

O casamento civil - ou seja, aquele que obedece a requisitos legais e formais e que não tem vínculo religioso - é reconhecido em todos os países que compóem a Uniáo Europeia desde que o casal seja composto por indivíduos de sexo diferente. Vale ressaltar, porém, que as regras aplicadas às chamadas "uniōes de fato" e às "parcerias registradas" não são aplicadas como no casamento. Deve-se, portanto, salientar que as regras relativas ao casamento variam para cada Estado membro da UE, principalmente no que se refere aos requisitos para que duas pessoas do mesmo sexo possam se casar (CASAMENTO..., 2016).

Alguns países da União Europeia como Portugal e o Reino Unido já aceitam formalmente o casamento entre pessoas do mesmo sexo. Assim, fica a cargo de cada Estado decidir a permissão e os direitos/responsabilidades dos casais homoafetivos. Devido a isso, há uma grande diferença dentro do bloco em relação a temas como herança, impostos e direitos a pensão (WELLE, 2013).

Uma vez que cada Estado possui autonomia para criar suas próprias legislaçôes, chega-se a um ponto de divergência entre as políticas supranacionais da União Europeia e a política interna de cada país. Diversas organizaçóes e associaçôes como a ILGA-Europe, juntamente com a Comissão Europeia, criticam a dificuldade e, muitas vezes, a falta de oportunidades de mudança para casais homossexuais dentro do bloco europeu (Por exemplo: se um casal de lésbicas de Portugal se mudar para a Alemanha, elas não terão os mesmos direitos que um casal heterossexual porque sua união não seria aceita juridicamente) (WELLE, 2013; FAMILY..., 2015).

A União Europeia busca incentivar as instituiçóes e governos dos Estados-membros a continuar trabalhando com este tema. Apesar disto, a Europa parece dividir-se, principalmente devido ao fator religioso, desta forma, atualmente apenas 13 países legalizaram o matrimônio entre pessoas do mesmo sexo. Vale ressaltar, que a União Europeia não tem competência para legislar diretamente sobre questóes relacionadas com a família (FAMILY..., 2015).

Os tribunais europeus, a Corte Europeia de Direitos Humanos e o Tribunal de Justiça da União Europeia já emitiram pareceres e posicionamentos favoráveis ao reconhecimento legal de casais do mesmo sexo e famílias LGBTI, mais especificamente relativos ao direito de desfrutar a vida familiar, ao direito de adotar, sem discriminação com base na orientação sexual, e aos direitos iguais aos pagamentos de pensão para parceiros casados (CASAMENTO..., 2016; FAMILY..., 2015). Ainda assim, em um panorama geral, os maiores avanços são referentes ações e iniciativas promovidas por ONGs e sociedade civil. Isso acontece em decorrência do fato de que, ainda que os órgãos competentes do bloco, como a Comissão Europeia e o Parlamento Europeu, apoiem e se comprometam com o tópico, não existe uma legislação comum voltada para o casamento igualitário.

\section{Eliminação da homotransfobia e políticas para a populaçáo trans}

Alguns avanços já foram realizados, no âmbito da União Europeia, voltados ao combate à discriminaçấo por orientação sexual e identidade de gênero. O Parlamento Europeu adotou, em 1989, a resolução OJ C 256/34, referente à discriminação contra transexuais. Com este documento o Parla- 
mento afirmou que os direitos individuais deveriam incluir também os direitos relacionados à identidade de gênero. Existe também o artigo 13 do Tratado de Amsterdam, de 1997, que se refere ao combate a qualquer tipo de discriminação, seja esta baseada em sexo, raça, religião, deficiência, idade ou orientação sexual (CASTAGNOLI, 2010).

No ano de 2000 foi adotada, pelo Conselho da União Europeia, a Diretiva de Igualdade no Emprego (2000/78/EC), que visa combater qualquer tipo de discriminação no ambiente de trabalho, incluindo aquela decorrente da orientação sexual. Já o Parlamento Europeu adotou, no ano de 2006, uma diretiva referente ao tratamento igualitário no ambiente de trabalho (Diretiva 2006/54/EC) que pela primeira vez contou com uma referência explícita à discriminação por mudança de sexo. A diretiva de 2006 levou em conta o posicionamento da Corte de Justiça da UE, que afirmou que legislações referentes ao tratamento igualitário são aplicáveis às pessoas transgêneras. A Corte também já determinou que este tratamento igualitário deva ser aplicado de acordo não com o sexo de nascença, mas com aquele posterior à mudança de sexo (CASTAGNOLI, 2010).

Apesar dos avanços mencionados acima, a questáo da identidade de gênero ainda é uma questão emergente e bastante controversa, o que torna difícil incluí-la nas discussóes públicas, na legislação da Uniấo Europeia e mais ainda na legislação dos Estados-membros do bloco (CASTAGNOLI, 2010). Outra dificuldade existente consiste em encontrar dados confráveis relativos à população transgênera na Europa e a discriminação em razão da identidade de gênero. Apesar da relação existente entre discriminação e exclusáo social já ter sido reconhecida pela Comissão Europeia e pelo Conselho Europeu em diversas ocasióes, ainda é preciso incluir preocupaçôes referentes à igualdade e não discriminação nas políticas sociais promovidas pelo bloco, uma vez que a discriminaçáo continua como uma das principais causas de exclusão (TAKÁCS, 2006).

A Comissão Europeia apresentou em 2015 o relatório referente à estratégia da União Europeia para igualdade entre homens e mulheres para os próximos quatro anos. O Parlamento Europeu aprovou o documento, que inclui questôes relacionadas à população transgênera. Apesar da aprovaçấo, houve significativa oposição de partidos conservadores e de direita, que fizeram lobby contra a inclusão de questóes relacionadas à população LGBTI, assim como temas como direitos sexuais e reprodutivos, entre eles o aborto. Também no ano de 2015 o Parlamento reconheceu a existência da discriminação generalizada, do assédio e da violência contra pessoas trans em toda a Uniáo Europeia. $\mathrm{O}$ órgáo também reiterou seu o pedido para que a Organização Mundial da Saúde (OMS) retire a classificação que caracteriza as pessoas trans como doentes mentais, que consta Classificação Internacional de Doenças (EU PARLIAMENT..., 2015).

Desta forma, fica evidente que ainda são necessários muitos avanços para a eliminação da homotransfobia e uma melhor assistência para esta população. As ações realizadas pela UE são iniciais e ainda enfrentam significativa resistência, seja dos partidos mais conservadores do Parlamento Europeu ou dos próprios Estados-membros em atuação na Comissão Europeia. São grandes as dificuldades de se definir uma agenda ou estratégia comum, maiores ainda as de promoção de ações, projetos e iniciativas voltados para este tema.

\section{Considerações Finais}

A partir das políticas analisadas, é possível observar que aquelas que mais apresentaram caráter supranacional foram as políticas de promoção da igualdade de gênero. Dentre as políticas das três áreas referentes à igualdade de gênero que foram 
analisadas (paridade salarial, violência de gênero e aborto), apenas na questão do aborto foram observadas maiores limitaçóes, enquanto nas políticas de todas as três áreas relativas à promoção dos direitos LGBTI (casamento homoafetivo, homotransfobia e políticas para transgêneros) foi possível identificar limitaçóes e barreiras para uma atuação de cunho mais supranacional.

No que diz respeito às políticas de promoção da paridade salarial e combate à violência contra a mulher, existe uma maior institucionalização acerca do tema, bem como é possível identificar uma agenda comum entre os Estados-membros. O tema se encontra nas principais agendas de discussão da Uniāo Europeia, existe uma atuação consistente da Comissão Europeia (através da adoção de diretivas, formulação de políticas e auxílio aos países) e não existe contraposição ou resistência significativa por parte dos Estados quanto ao tema. É possível observar, portanto, uma harmonização quanto a estas questôes, o que permite uma construção de políticas ou acordos institucionais de caráter mais supranacional. Relativamente ao aborto, no entanto, não ocorre o mesmo. As políticas de aborto náo conseguem ser acordadas em conjunto na Uniâo Europeia, principalmente devido ao posicionamento contrário de alguns países como Malta e Irlanda, que se opóem e prejudicam o avanço de políticas comuns e programas da Comissão Europeia relativos à questão.

Quanto às políticas de promoção de direitos LGBTI, apesar da tentativa de inclusão do tema nas agendas de discussōes mais recentes da União Europeia, elas ainda não apresentam um caráter de fato supranacional. A questão consiste em uma discussão recente e ainda encontra resistência incisiva de alguns Estados-membros e de grupos e partidos nacionais de cada Estado, até mesmo para o debate acerca do tema, o que dificulta a construção de uma agenda comum, bem como de políticas e acordos institucionais conjuntos referentes ao tema. Não é possível ob- servar, nas açóes de promoção dos direitos LGBTI, o mesmo nível de harmonização presente nas ações de promoçâo da igualdade de gênero.

É importante ressaltar, no entanto, que tanto o spillover quanto a harmonização não acontecem de forma automática nem rápida, são processos graduais e que demandam tempo. Há dez anos, não existia o mesmo nível de coesão entre os Estados-membros da Uniấo Europeia quanto às questôes de igualdade de gênero, nem todas as políticas de caráter supranacional sobre o tema atualmente em vigor.

Outro ponto relevante diz respeito às barreiras para os avanços dos debates permeadas pelas questóes identitárias. Ainda que exista a expectativa de que essas pautas avancem com o decorrer do tempo, observa-se que tanto nas açóes voltadas para a promoção de direitos para a população LGBTI, quanto no que se refere ao aborto, existe a presença de grupos que fazem oposição até mesmo à inclusão dessas áreas nas pautas de discussão da União Europeia. Existe a possibilidade de que a oposição desses grupos decorra do fato de que estes percebam a identidade do bloco como incompatível com a identidade específica do grupo, pelo menos no que se refere a estas temáticas específicas. Assim, ainda que existam limitaçóes significativas para o spillover e harmonização na promoção dos direitos LGBTI, espera-se que com o tempo e a ação política dos grupos e organizaçóes interessados no tema, estas sejam gradualmente superadas.

\section{Referências}

BALE, Tim. European politics. 2. ed. Nova Iorque: Palgrave Macmillan, 2008.

BERGER, Peter. Identity as a problem in the sociology of knowledge. European Journal of Sociology. v. 7, n. 1, p. 105-115, 1966.

CASTAGNOLI, Cristina. Transgender persons' rights in the UE member states. Brussels: Directorate General for Internal Policies. 2010.

COUNCIL OF EUROPE. Key legal instrument. 2014. 
Disponível em: <http://www.coe.int/t/dg4/lgbt/Documents/ Instruments_EN.asp $>$. Acesso em: 10 nov. 2015. Acesso em: 10 nov. 2015

COUTINHO, Luís P. Pereira. Instituiçóes políticas supranacionais: algumas notas.[S.I.]: ICJP, 2016. Disponível em: $<$ http://www.icjp.pt/sites/default/files/media/757-1152.pdf . Acesso em: 15 abr. 2016.

BARBIÈRE, Cécile. EU Divided over abortion in development policy. Translated by Samuel White. France: EURACTIV, 11 maio 2015. Disponível em: <www.euractiv.com/ sections/development-policy/eu-divided-over-abortion-development-policy-314455> Acesso em: 6 nov. 2015.

CASAMENTO: o casamento civil é um estado civil reconhecido em todos os países da UE. [S.I]: EUROPA.EU, 2016. Disponível em: <http://europa.eu/youreurope/citizens/family/couple/marriage/index_pt.htm>. Acesso em: 09 nov. 2015. CONSELHO EUROPEU DE LISBOA. Conselho europeu extraordinário de Lisboa (Março de 2000): para uma europa da inovaçấo e do conhecimento. Lisboa: EUR-LEX, 2006. Disponível em: <http://eur-lex.europa.eu/legalcontent/PT/ TXT/?uri=URISERV\%3Ac10241>. Acesso em: 01 abr. 2016.

DIRECTIVE 2006/54/EC of the european parliament and of the council of 5 July 2006 on the implementation of the principle of equal opportunities and equal treatment of men and women in matters of employment and occupation (recast). Official Journal of the European Union, Strasbourg, 2006. Disponível em: < http://eur-lex.europa.eu/legal-content/EN/ TXT/HTML/?uri=CELEX:32006L0054\&from=EN>. Acesso em: 07 nov. 2015.

DIRECTIVE 2011/36/EU of the European Parliament and of the Council of 5 April 2011 on preventing and combating trafficking in human beings and protecting its victims, and replacing Council Framework Decision 2002/629/JHA. Official Journal of the European Union, 2011a. Disponível em: < http://eur-lex.europa.eu/LexUriServ/LexUriServ.do?uri=OJ:L:2011:101:0001:0011:EN:PDF>. Acesso em: 07 nov. 2015. DIRECTIVE 2011/92/EU of the European Parliament and of the Council of 13 December 2011 on the assessment of the effects of certain public and private projects on the environment. Official Journal of the European Union, 2011b. Disponível em: <http://eurlex.europa.eu/LexUriServ/LexUriServ. do?uri=OJ:L:2012:026:0001:0021:En:PDF>. Acesso em: 07 nov. 2015.

DIRECTIVE 2011/99/EU of the european parliament and of the council of 13 December 2011 on the european protection order. Official Journal of the European Union, 2011c. Disponível em: <http://ec.europa.eu/justice/criminal/files/directive_2011_99_on_epo_en.pdf>. Acesso em: 07 nov. 2015.

DIRECTIVE 2012/29/EU of the european parliament and of the council of 25 October 2012 establishing minimum standards on the rights, support and protection of victims of crime, and replacing Council Framework Decision
2001/220/JHA. Official Journal of the European Union, 2012. Disponível em: <http://eur-lex.europa.eu/LexUriServ/ LexUriServ.do?uri=OJ:L:2012:315:0057:0073:EN:PDF>. Acesso em: 07 nov. 2015.

EU PARLIAMENT demands trans-inclusive EU gender equality strategy. [S.1.]: TGEU, 2015. Disponíel em: <http://tgeu. org/eu-parliament-demands-trans-inclusive-eu-gender-equality-strategy/>. Acesso em: 10 nov. 2015.

EUROPEAN COMISSION. Report on equality between women and men. Luxembourg: Publications Office of the European Union, 2015. Disponível em: <http://ec.europa.eu/ justice/gender-equality/files/annual_reports/150324_annual_ report_2014_web_en.pdf>. Acesso em: 07 nov. 2015.

EUROPEAN UNION. Regulations, directives and other acts. [S.1.]: EUROPA.EU, 2015a. Disponível em: <http:// europa.eu/eu-law/decision-making/legal-acts/index_en.htm>. Acesso em: 07 nov. 2015.

EUROPEAN COMISSION. Gender equality in the European Union. Luxemburgo: Escritório de Publicaçôes da União Europeia, 2011.

EUROPEAN COMISSION. Communication from the commission to the European Parliament and the Council towards the elimination of female genital mutilation. Brussels: EUROPA.EU, 2013. Disponível em: <http://ec.europa.eu/justice/genderequality/files/gender_based_violence/131125_fgm_communication_en.pdf $>$. Acesso em: 07 nov. 2015.

EUROPEAN COMISSION. Boosting equality between women and men in the EU: key actions and figures. [S.1.]: EUROPA.EU, 2014a. Disponível em: <http://ec.europa.eu/ justice/genderequality/files/documents/140303_factsheet_ progress_en.pdf $>$. Acesso em: 07 nov. 2015.

EUROPEAN COMISSION. Commission recommendation of 7.3.2014 on strengthening the principle of equal pay between men and women through transparency. Brussels: EUROPA.EU, 2014b. Disponível em: <http://ec.europa.eu/ justice/gender-equality/files/gender_pay_gap/c_2014_1405_ en.pdf>. Acesso em: 07 nov. 2015.

EUROPEAN COMISSION. European commission actions to combat violence against women. [S.l.]: EUROPA.EU, 2015. Disponível em: <http://ec.europa.eu/justice/gender-equality/files/documents/140303_factsheet_vaw_en.pdf>. Acesso em: 07 nov. 2015.

FAMILY: what do ILGA-Europe mean when we talk about 'family'? [S.I.]: ILGA-EUROPE, 2015. Disponível em: <http:// www.ilga-europe.org/what-we-do/our-advocacy-work/family>. Acesso em: 08 nov. 2015.

HAAS, Ernst B. Regional integration. In: GALE, Thomas. International encyclopedia of social sciencies. New York: Macmillan, 2008. Disponível em: <http://www.encyclopedia.com/ doc/1G23045000593.html>. Acesso em 12 nov. 2015

HAAS, Ernst B.The study of regional integration: reflections 
on the joy and anguish of pretheorizing. International Organization, Cambridge, v. 24, n. 4, 1971.

INSTITUTO EUROPEU PARA A IGUALDADE DE GÊNERO. Estimating the costs of gender-based violence in the European Union: Report. Luxembourg: European Union, 2014. Disponível em: <http://eige.europa.eu/sites/default/ files/documents/MH0414745ENC.pdf>. Acesso em: 07 nov. 2015.

KAISER, Karl. A política transnacional: para uma teoria da política multinacional. In: BRAILLARD, Philippe. Teoria das Relaçóes Internacionais. Lisboa: Fundação Calouste Gulbenkian, 1990.

KEOHANE, Robert. After hegemony: coopeartion and discord in the world political economy. Pinceton: Princeton University University Press, 1984. Disponível em: <http://people. iq.harvard.edu/ olau/ir/archive/keo8.pdf $>$. Acesso em: 12 nov. 2015

LEACH, Rodney. European Union: a concise encyclopedia of the European Union. 3rd Edition. London: Profile Books, 2000.

MAMEDE, Anna Paula Ribeiro Araujo. Procedimentos democráticos, resultados Conservadores? os novos poderes institucionais do Parlamento Europeu e a política migratória europeia após o Tratado de Lisboa. 2014. 130f. Dissertaçáo (Mestrado) - Programa de Pós-Graduação Stricto Sensu em Relaçōes Internacionais. Pontifícia Universidade Católica de Minas Gerais. 2014. Disponível em: < http://www.opiniaopublica.ufmg.br/site/files/biblioteca/RelInternac-MamedeAP. pdf>. Acesso em: 10 mar. 2016.

NIEMANN, Arne; SCHMITTER, Philippe C. Neofunctionalism. In: WIENER, Antje; DIEZ, Thomas. European integration theory. Oxford: Oxford University Press, 2009. Cap. 3, p. 45-66.

RAMOS, Leonardo; MARQUES, Sylvia Ferreira; JESUS, Diego Santos Vieira. A Uniáo Européia e os estudos de integraçáo regional. Coordenador Leonardo Nemer Caldeira Brant. Belo Horizonte: Del Rey, 2009.

REACH, Rodney. Europe: a concise encyclopedia of the european union: from Aachen to Zollverein. London: Routledge, 2000. Disponível em: <http://www.euroknow.org/europages/ dictionary/index.html>. Acesso em: 11 nov. 2015

REGULATION (EU) No 606/2013 of the European Parliament and of the Council of 12 June 2013 on mutual recognition of protection measures in civil matters. Official Journal of the European Union, 2013. Disponível em: <http://eur-lex.europa.eu/LexUriServ/LexUriServ.do?uri=OJ:L:2013:181:0004:0012:en:PDF>. Acesso em: 07 nov. 2015.

RISSE, Thomas. Social constructivism and european integration. In: WIENER, Antje; DIEZ, Thomas. European Integration Theory. Oxford: Oxford University Press, 2009. Cap. 8, p. $143-160$.
ROY, Olivier. The (re)construction and formatting of religions in the west through courts, social practices, public discourse and transnational institutions. [S.1.]: European University Institute, 2016. Disponível em: <http://www.iris-france.org/wp-content/uploads/2016/03/RW-rethinking-the-place-of-religion.pdf>. Acesso em: 01 abr. 2016.

SANTOS, Sergio Caballero. Regional integration theories: the suitability of a

constructivist approach (at least, in the case of South America). 2009. In: GLOBALISATION AND GOVERNANCE, Anais... Paper 383, Panel 230, Session RC-17, Chile, Jul. 2009. Disponível em: < https://www.academia.edu/1368121/ Regional_Integration_Theories_The_Suitability_of_a_Constructivist_Approach_at_least_in_the_case_of_South_America_?auto=download $>$. Acesso em: 15 jun. 2016.

SEDGH, Gilda et al. Legal abortion worldwide: incidence and recent trends. International

Family Planning Perspectives, v.33, n.3, p. 106-116, 2007.

TAKÁCS, Judit. Social exclusion of young lesbian, gay, bisexual and transgender (LGBT) people in Europe. Brussels, Belgium: ILGA Europe, 2006.

UNIÃO EUROPEIA. Instituiçóes e outros organismos da EU. [S.1.]: EUROPA.EU, 2016. Disponível em: <http://europa.eu/about-eu/institutions-bodies/index_pt.htm>. Acesso em: 01 abr. 2016.

WELLE, Deustche. Casamento gay testa os limites da tolerância na Europa. Carta Capital. 04 abr. 2013. Disponível em: $<$ http://www.cartacapital.com.br/internacional/casamento-gay-testa-os-limites-da-tolerancia-na-europa $>$. Acesso em: 04 nov.2016. 